\title{
Critical Appraisal on Randomized Controlled Trial to Improve Care for Urban Children with Asthma
}

\section{Nadia Mahmoud AA*}

Ministry of Health, Khartoum, Sudan

*Corresponding author: Nadia Mahmoud Ali Abuzied, Ministry of Health, Khartoum, Sudan, Email: dr.nadiaali@hotmail.com

\section{Research Article \\ Volume 3 Issue 2}

Received Date: September 09, 2019

Published Date: November 04, 2019

DOI: $10.23880 /$ phoa- 16000146

\section{Abstract}

Objective-to evaluate the impact of the School-Based Asthma Therapy trial on asthma symptoms among urban children with persistent asthma. Design-Randomized trial, with children stratified by smoke exposure in the home and randomized to a school-based care group or a usual care control group. Setting-Rochester, New York. ParticipantsChildren aged 3 to 10 years with persistent asthma. Interventions-Directly observed administration of daily preventive asthma medications by school nurses (with dose adjustments according to National Heart, Lung, and Blood Institute Expert Panel guidelines) and a home-based environmental tobacco smoke reduction program for smoke-exposed children, using motivational interviewing. Main Outcome Measure-Mean number of symptom-free days per 2 weeks during the peak winter season (November-February), assessed by blinded interviews. Results-We enrolled 530 children (74\% participation rate). During the peak winter season, children receiving preventive medications through school had significantly more symptom-free days compared with children in the control group (adjusted difference=0.92 days per 2 weeks;95\% confidence interval, 0.50-1.33) and also had fewer nighttime symptoms, less rescue medication use, and fewer days with limited activity (all $\mathrm{P}<.01$ ). Children in the treatment group also were less likely than those in the control group to have an exacerbation requiring treatment with prednisone $(12 \%$ Vs $18 \%$, respectively; relative risk $=0.64 ; 95 \%$ confidence interval, 0.41-1.00). Stratified analyses showed positive intervention effects even for children with smoke exposure ( $n=285$; mean symptom-free days per 2 weeks: 11.6 for children in the treatment group Vs 10.9 for those in the control group; difference $=0.96$ days per 2 weeks; 95\% confidence interval, 0.39-1.52).Conclusions-The School-Based Asthma Therapy intervention significantly improved symptoms among urban children with persistent asthma. This program could serve as a model for improved asthma care in urban communities.

Keywords: Critical Appraisal; Improve Care; Urban Children; Asthma 


\section{Introduction}

Asthma Is One of The Most common chronic conditions of childhood and is responsible for substantial morbidity and cost [1,2]. Inflammation is a key component of asthma, and inhaled corticosteroids are the most effective long-term therapy for children with persistent asthma $[3,4]$. The National Heart, Lung, and Blood Institute Expert Panel guidelines recommend that all children with persistent asthma receive daily preventive anti-inflammatory medications [5,6]. Despite these recommendations, many children who should receive these medications do not receive them [7].

Poor and minority children have the greatest morbidity from asthma [8-11] and also are the group least likely to receive adequate preventive therapy [12-14]. These children also are frequently exposed to environmental triggers, including environmental tobacco smoke (ETS), [15-19] that worsen symptoms and make management more difficult [20-23]. There currently are few interventions for urban children with asthma that ensure children are receiving appropriate preventive care $[24,25]$.

We implemented the School-Based Asthma Therapy trial to reduce morbidity for impoverished children with asthma by improving adherence to care guidelines [26]. This study builds on our experience with a pilot study that included 180 urban children in which we found that directly observed therapy using preventive asthma medications in school reduced asthma symptoms [27]. However, the beneficial effects of that program on asthma symptoms were seen only among children not exposed to smoke. Because this type of school-based program has the potential to substantially improve care for impoverished children with asthma, we sought to establish the following: (1) whether these findings could be replicated in a similar school-based study of directly observed therapy, including a larger sample of urban children; (2) whether the effects could be enhanced by even more stringent adherence to care guidelines through the addition of symptom-based medication dose adjustments; and (3) whether children exposed to smoke would have greater benefit from the school-based intervention when combined with an ETS reduction program. Our primary hypothesis was that children receiving the intervention would have more symptom-free days during the peak winter season (November-February) compared with children in a usual care control group. Our secondary hypothesis was that among the subgroup of smokeexposed children, those who received the school-based

Nadia Mahmoud AA. Critical Appraisal on Randomized Controlled Trial to Improve Care for Urban Children with Asthma. Public H Open Acc 2019, 3(2): 000146. intervention with ETS reduction would experience less asthma morbidity than those who received usual care.

\section{Methods}

\section{Participants}

The University of Rochester Institutional Review Board approved the study protocol. We recruited children aged 3 to 10 years attending preschool or elementary school in the Rochester City School District. Eligibility required the child to be enrolled in the Rochester City School District and have physician-diagnosed asthma (by parent report with physician validation) with persistent symptoms based on National Heart, Lung, and Blood Institute Expert Panel guidelines.5,6 Children were excluded if they had other medical conditions that could interfere with the assessment of asthma-related outcomes (cystic fibrosis, congenital heart disease, other lung disease), if the primary caregiver was unable to speak and understand English, if they were planning to leave the school district within 6 months, or if they had no access to a telephone for follow-up surveys (at home or an easily accessible alternate location).

\section{Procedures}

Enrollment occurred during the beginning of 3 consecutive school years starting in 2006, from late August through mid-November. Parents of children with asthma indicated on their school health forms received a telephone survey to determine eligibility. Once a child was deemed eligible, the study was explained in detail and permission was obtained to contact the child's primary care provider (PCP). The PCP for each child had to authorize his or her participation and agree with the child's need for a daily inhaled corticosteroid prior to randomization. We then used home visits to elicit informed consent and obtain baseline measurements. Details of the assessment have been reported.26 following the baseline assessment; children were assigned to the treatment or control group by blocked randomization in a 1:1 ratio. The randomization scheme was created by the biostatistics center and was stratified by smoke exposure based on the question, "How many people in this child's home smoke?" ( 0 vs $\geq 1)$. The intervention continued for 1 school year (7-9 months).

\section{Treatment Group}

For each child in the treatment group, medication (fluticasone propionate or fluticasone with salmeterol xinafoate) and a spacer (as appropriate) were delivered to the school nurse for directly observed therapy on the 
days on which the child attended school. The school nurse (or health aide) was instructed to deliver 1 dose of medication to the child during the school day. We used once-daily dosing because it can be effective 28 and it allows for administration during school hours. The time of dose delivery varied by child and coincided with the routine time most convenient for the student and nurse. The nurses used medication administration logs; children received their preventive medication $98 \%$ of the time they were in school. An additional canister of preventive medication was delivered to the child's home to use on weekends and other days the child did not attend school, and the child's caregiver was shown proper administration technique. While adherence to medication administration was ensured by the nurse on the days the child attended school, adherence was simply encouraged on days on which the child did not attend school (including weekends, vacations, and days absent). The medication administered through the study varied depending on the child's baseline asthma therapy. The study team reviewed medication doses with the child's PCP prior to the start of the study, and adjustments were made at the PCP's discretion. Assessment for possible step-up in therapy occurred during the first 3 months of the intervention. The schematic for starting medications and dose adjustments has been presented [28].

Information regarding planned changes in the child's regimen was relayed to the PCP and family, and both parties agreed prior to implementation of an adjusted dose. At the end of the school year, PCPs were notified that the children would no longer receive medications through school, and the PCP could decide to continue or step down therapy at that time. Families of smokeexposed children in the treatment group also received an ETS reduction program. We used motivational interviewing principles to counsel the primary caregiver about reducing smoke in the home and to provide brief smoking cessation counseling with the primary caregiver (if a smoker) and an additional smoker who spends the most time with the child. Motivational interviewing is a patient-centered counseling style designed to reduce ambivalence about change and increase intrinsic motivation for change $[29,30]$. This intervention was adapted from 2 previous studies [31,32] and consisted of a 20- to 30-minute in-home counseling session 2 to 3 weeks after baseline and 2 follow-up telephone counseling calls (10-15 minutes each) 1 and 3 months after the in-person visit. Primary caregivers and the smoker in the household were counseled separately. The intervention was delivered by 2 registered nurses (P.T. and Susan Blaakman, MS, RN, NPP-BC) trained by a certified motivational interviewing trainer (B.B.). All counseling sessions were audiotaped, and more than $20 \%$ were reviewed for fidelity to the protocol and to motivational interviewing.

\section{Control Group}

Caregivers of children in the control group were encouraged to contact their PCP to discuss the child's persistent asthma symptoms. Families were responsible for filling prescriptions from their PCPs and administering medications daily to the child. No medications were provided by the study team, and no ETS counseling was provided for smoke-exposed children in this group.

\section{Outcomes}

All families were given diaries to track their child's symptoms. Outcomes were assessed by monthly telephone interviews by an independent research group blinded to group allocation. The primary outcome measure was the number of symptom-free days during 2 weeks averaged across the peak asthma season (November-February) [33]. Parents were asked to refer to their diaries and report the number of days their child experienced no symptoms of asthma (defined as a 24hour period with no coughing, wheezing, chest tightness, or shortness of breath and no need for rescue medications) during the past 2 weeks. Secondary symptom measures included the numbers of nights with asthma symptoms, days with activity limitation, days needing rescue medications, and days of missed school due to asthma. Parents were asked to report the number of acute office and emergency department visits and hospitalizations for asthma that their child required since the prior telephone interview. We defined an acute exacerbation as any visit for asthma where prednisone was prescribed. We collected saliva samples from each child at the beginning and end of the study to determine the child's level of cotinine, a metabolite of nicotine, using standard methods. All samples were measured with a standard enzyme-linked immunosorbent assay (Salimetrics, LLC, and State College, Pennsylvania). In addition, we assessed standard demographic variables 26 as well as caregiver depression [34]. Medical records were reviewed for $10 \%$ of the sample to confirm office and emergency department visits and hospitalizations; visits were confirmed in $83 \%$ of cases.

\section{Statistical Analysis}

Subjects were kept in their originally assigned groups for analysis. Demographic variables and baseline outcomes were compared to confirm balance between 
randomized groups using t tests or $\chi 2$ tests. Continuous variables were analyzed using a linear mixed-effects model, with indicator of treatment and treatment $\times$ time interaction as independent variables. The analyses were repeated after controlling for baseline outcomes, child's sex, age, race, insurance, caregiver's education, maternal depression, and cotinine level. The treatment effect was regarded as fixed and the subjects were regarded as the random effect, with an autoregressive heterogeneous variance covariance structure specified. Categorical outcomes were analyzed using a generalized estimating equation model with a log-link function and Poisson error to obtain robust estimations of treatment effects. We tested interactions between treatment and smoke exposure and conducted stratified analyses. The PROC MIXED and PROC GENMOD procedures (SAS version 9.2 statistical software; SAS Institute, Inc, Cary, North Carolina) were used for fitting the models. We powered our trial for analysis on the primary outcome, symptomfree days. Based on our pilot data,27 a sample of 480 provides $84 \%$ power to detect a difference of 1.1 symptom-free days per 2 weeks, based on a 2 -sided t test $(\alpha=.025)$.

\section{Results}

We screened 2252 children with asthma indicated on their school health records (Figure 1), and 713 were eligible for the program. We enrolled 530 children from 67 schools and preschools, for a participation rate of $74 \%$ (530 of 713 children). A total of 523 subjects (99\%) had data for the primary analysis. There were no differences in demographic characteristics between children in the 2 study groups (Table 1). The children's mean age was 7.1 years, and more than half were male (58\%), black (63\%), and covered by Medicaid (73\%). In addition, 54\% of the children lived with a smoker and 69\% reported using a preventive medication at baseline. Asthma symptoms were similar at baseline, with children in both groups having an average of 8 symptom-free days per 2 weeks. Table 2 summarizes the primary outcomes by group. During the peak winter season, children in the treatment group experienced more symptom-free days compared with children in the control group (mean symptom-free days per 2 weeks, 11.6 vs 10.7, respectively). Children in the treatment group also had significantly fewer nights with symptoms, fewer days with activity limitation, less rescue medication use, and fewer days absent from school due to asthma compared with children in the control group. The analyses were repeated controlling for baseline symptoms and covariates. Treatment was associated with an additional 0.92 symptom-free day per 2 weeks, on average, compared with the control group (95\% confidence interval [CI], 0.50 to 1.33). Full-year outcomes also showed a significant treatment effect (difference $=0.73$ symptom-free days per 2 weeks; 95\% CI, 0.43 to 1.04). While children's cotinine level was associated with the outcomes, the intervention effect was independent of change in cotinine levels. The mean (SD) end-of-year cotinine values were $1.05(1.49) \mu \mathrm{g} / \mathrm{L}$ for children in the treatment group and $1.16(1.94) \mu \mathrm{g} / \mathrm{L}$ for children in the control group (difference $=-0.11 \mu \mathrm{g} / \mathrm{L} ; 95 \%$ CI, -0.19 to 0.42 ) (to convert to Nano moles per liter, multiply by 5.675$)$. Children in the treatment group were less likely to have an exacerbation requiring prednisone throughout the study period compared with children in the control group ( $12 \%$ vs $18 \%$, respectively). When controlling for covariates, the intervention was associated with a $36 \%$ reduction in asthma exacerbations compared with the control group (relative risk $=0.64 ; 95 \% \mathrm{CI}, 0.41$ to 1.00). For emergency department visits, acute office visits, and hospitalizations individually, the visit rates were lower for children in the treatment group but there were no significant differences. At the end of the study, $49 \%$ of children in the treatment group were receiving fluticasone and 51\% were receiving fluticasone with salmeterol. In the control group, $60 \%$ reported using preventive asthma medication (29\% fluticasone, $11 \%$ fluticasone with salmeterol, and $21 \%$ other). Figure 2 illustrates the number of symptom-free days per 2 weeks by month for the children in the treatment and control groups during the peak winter season. Both groups demonstrated improvement over time $(\mathrm{P}=.005$ for the control group; $\mathrm{P}<.001$ for the treatment group). However, children in the treatment group experienced more symptom-free days compared with children in the control group, and by February they were experiencing a mean of 1.2 additional symptom-free days per 2-week period (95\% CI, 0.59 to 1.80$)$.

\begin{tabular}{|c|c|c|c|}
\hline Demographic Variable & Overall (N=530) & Treatment Group (n=265) & Control Group (n=265) \\
\hline Child's age, mean (SD). y & $7.1(1.9)$ & $7.1(2.0)$ & $7.2(1.9)$ \\
\hline Male child, No. (\%) & $308(58)$ & $161(61)$ & $147(56)$ \\
\hline \multicolumn{3}{|c|}{ Child's race. No. (\%) } \\
\hline White & $48(9)$ & $27(10)$ & $21(8)$ \\
\hline Black & $335(63)$ & $167(63)$ & $168(63)$ \\
\hline
\end{tabular}




\begin{tabular}{|c|c|c|c|}
\hline Other & $147(28)$ & $71(27)$ & $76(29)$ \\
\hline \multicolumn{4}{|c|}{ Insurance. No. (\%) } \\
\hline Medicaid & $389(73)$ & 192(72) & $197(74)$ \\
\hline New York's SCHIP & $64(12)$ & $33(12)$ & $32(12)$ \\
\hline Private or other & $63(12)$ & $35(13)$ & $28(11)$ \\
\hline No insurance & $14(3)$ & $5(2)$ & $9(3)$ \\
\hline Hispanic ethnicity, No. (\%) & $151(28)$ & $82(31)$ & $69(26)$ \\
\hline$\geq 1$ Smoker in the home, No & $285(54)$ & $140(53)$ & $145(55)$ \\
\hline Cotinine level, mean(SD). $\mu \mathrm{g} / \mathrm{l}$ & $1.41(2.31)$ & $1.25(1.61)$ & $1.57(2.83)$ \\
\hline $\begin{array}{c}\text { Reported preventive medications at baseline } \\
\text { No. }(\%)\end{array}$ & $364(69)$ & $186(70)$ & $178(67)$ \\
\hline $\begin{array}{c}\text { Caregiver's education less than high school. No. } \\
(\%)\end{array}$ & 205(39) & $106(40)$ & $99(37)$ \\
\hline Maternal depression. Mean (SD). score & $19.7(9.1)$ & $19.9(9.4)$ & $19.5(8.9)$ \\
\hline \multicolumn{4}{|c|}{ Baseline asthma severity in past $2 \mathrm{wk}$} \\
\hline Symptom-free days, mean (SD), No & $8.0(4.8)$ & $8.0(5.0)$ & $8.0(4.8)$ \\
\hline Symptom nights, mean (SD), No & $4.1(4.5)$ & $4.0(4.5)$ & $4.1(4.5)$ \\
\hline Days with activity limitation, mean (SD). No. & $3.0(3.8)$ & $2.9(3.8)$ & $3.0(3.8)$ \\
\hline $\begin{array}{l}\text { Days with rescue medication use. mean (SD). } \\
\text { No. }\end{array}$ & $4.0(4.6)$ & $4.1(4.8)$ & $3.9(4.5)$ \\
\hline $\begin{array}{c}\text { Any emergency department visit in past year. } \\
\text { No. (\%) }\end{array}$ & 209 (39) & $104(39)$ & $105(40)$ \\
\hline$\geq 1$ Hospitalization in past year, No. (\%) & $26(5)$ & $14(5)$ & $12(4)$ \\
\hline
\end{tabular}

Table 1: Population demographic variables and baseline morbidity.

Abbreviation: SCHIP. State Children's Health Insurance Program. SI conversion factor. To convert cotinine to Nano moles per liter, multiply by 5.675 .

\begin{tabular}{|c|c|c|c|c|}
\hline Outcome & $\begin{array}{c}\text { Treatment Group } \\
(\mathbf{n = 2 6 0 )}\end{array}$ & $\begin{array}{c}\text { Control Group } \\
(\mathbf{n = 2 6 3 )}\end{array}$ & $\begin{array}{c}\text { Difference (95\% CI) or RR } \\
\text { (95\% CI) }^{\mathbf{a}}\end{array}$ & $\mathbf{p ~ V a l u e ~}^{\mathbf{a}}$ \\
\hline \multicolumn{2}{|c|}{ Symptoms in peak winter season, November-February, mean (SD) } \\
\hline Symptom-free days/2 wk & $11.6(2.5)$ & $10.7(3.1)$ & $0.92(0.50 \text { to } 1.33)^{\mathrm{b}}$ & 0.001 \\
\hline Symptom nights/2 wk & $1.7(2.2)$ & $2.3(2.5)$ & $-0.68(-1.01 \text { to }-0.35)^{\mathrm{b}}$ & 0.001 \\
\hline Days with activity limitation/2 wk & $1.3(2.0)$ & $1.8(2.3)$ & $-0.47(-0.78 \text { to }-0.16)^{\mathrm{b}}$ & 0.003 \\
\hline Days with rescue medication use/2 wk & $1.6(2.2)$ & $2.6(2.7)$ & $-1.06(-1.41 \text { to }-0.72)^{\mathrm{b}}$ & 0.001 \\
\hline Days absent due to asthma/2 wk & $0.3(0.7)$ & $0.5(0.7)$ & $-0.17(-0.28 \text { to }-0.06)^{\mathrm{b}}$ & 0.002 \\
\hline \multicolumn{7}{|c|}{ Visits for asthma, No.(\%) c } & $0.60(0.28 \text { to } 1.30)^{\mathrm{d}}$ & 0.2 \\
\hline Emergency department visit & $13(5)$ & $19(7)$ & $0.74(0.44 \text { to } 1.22)^{\mathrm{d}}$ & 0.23 \\
\hline Acute office visit & $23(9)$ & $33(12)$ & NA & .67 \\
\hline Hospitalization & 0 & $2(1)$ & $0.64(0.41 \text { to } 1.00)^{\mathrm{d}}$ & 0.05 \\
\hline
\end{tabular}

Table 2: Primary study Outcomes.

Abbreviations: CI. Confidence interval; NA, not applicable; RR, relative risk.

aResults of the multivariate analysis are adjusted for baseline symptoms, child's age, sex, race, caregiver's education, insurance, maternal depression, and smoke exposure.

bValues are expressed as difference $(95 \% \mathrm{CI})$.

cDefined as a visit to the emergency department. office, or hospital where prednisone was prescribed. during the entire study period $(\mathrm{n}=525)$

dValues are expressed as RR (95\% CI).

eEstimate is from exact logistic regression. 


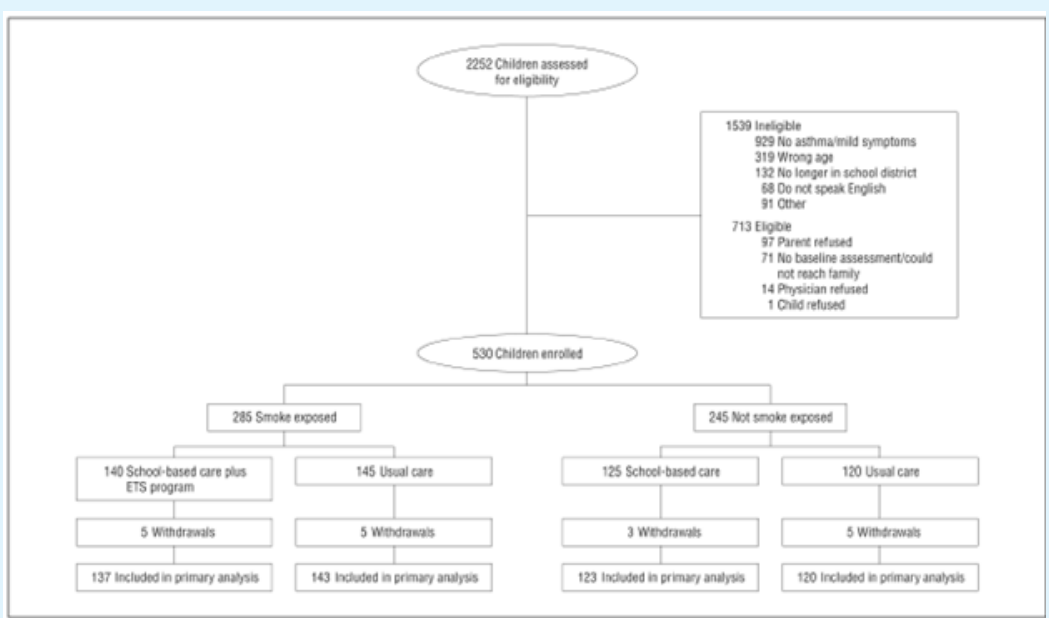

Figure 1: Enrollment flow diagram. ETS indicates environmental tobacco smoke.

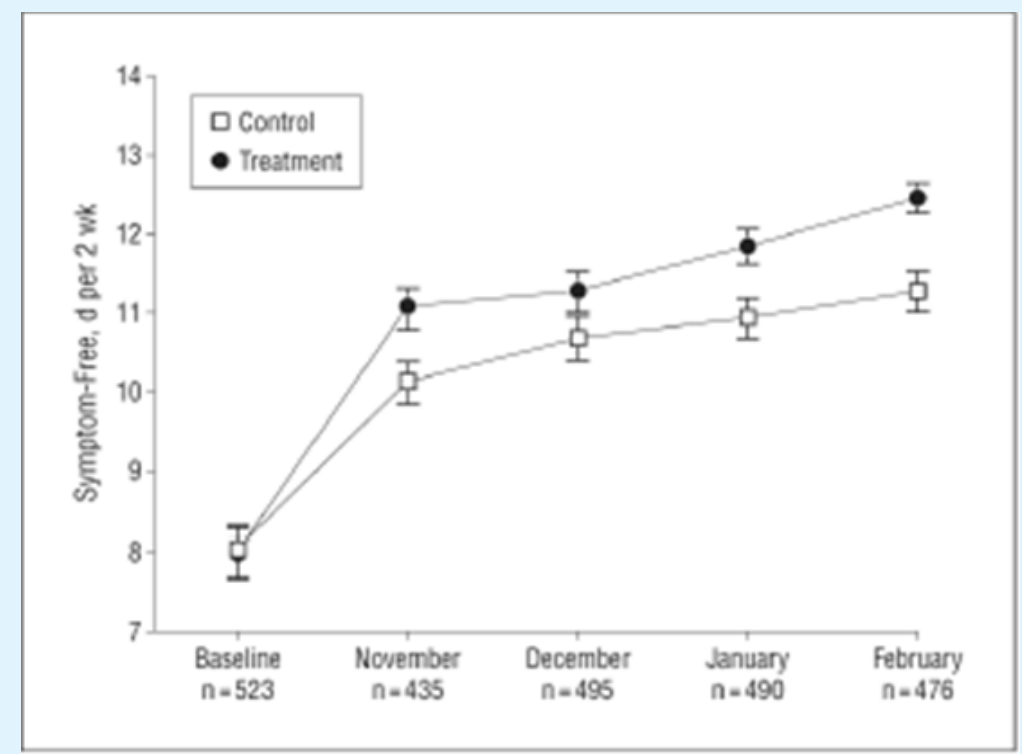

Figure 2: Mean symptom-free days per 2 weeks by month In November, January, and February, children in the treatment group had significantly more symptom-free days than children in the control group $(\mathrm{p}=.02, .005$, and $<.001$, respectively).

We next considered the primary study outcome separately for children without and with smoke exposure in the home (Table 3). There was no significant treatment smoke exposure interaction effect $(\mathrm{P}=.07)$. Stratified analysis showed positive treatment effects for symptom free days for children without smoke exposure (mean symptom-free days per 2 weeks, 11.6 for the treatment group vs 10.5 for the control group; adjusted difference $=0.91 ; 95 \%$ CI, 0.31 to 1.51 ) and for children with smoke exposure (mean symptom-free days per 2 weeks, 11.6 for the treatment group vs 10.9 for the control group; adjusted difference $=0.96$; $95 \% \mathrm{CI}, 0.39$ to 1.52 ), suggesting an effect of the intervention for both groups of children. Similar results also were present for the other outcome measures. Comparisons between subjects with complete data and those without complete data showed that baseline symptom-free days and race were associated with missing outcomes. Missing data 
were imputed using a multiple imputation algorithm based on multiple regressions, and multiple imputation inference was carried out $[35,36]$. The result showed a treatment effect similar to that shown by the primary analysis; the treatment group had 0.91 additional symptom-free day per 2 weeks compared with the control group (95\% CI, 0.49 to 1.33 ). There were no significant adverse events in either group.

\begin{tabular}{|c|c|c|c|c|c|c|}
\hline \multirow[b]{2}{*}{ Outcome } & \multicolumn{3}{|c|}{ No Smoke Exposure in Home } & \multicolumn{3}{|c|}{ Smoke Exposure in Rome } \\
\hline & $\begin{array}{c}\text { Treatment } \\
\text { Group } \\
(\mathbf{n}=123)\end{array}$ & $\begin{array}{c}\text { Control } \\
\text { Group }(n=120\end{array}$ & \begin{tabular}{|c|} 
Difference $(95 \%$ \\
CI) or RR (95\% \\
CI)
\end{tabular} & $\begin{array}{l}\text { Treatment } \\
\text { Group } \\
(\mathrm{n}=137)\end{array}$ & \begin{tabular}{c|} 
Control \\
Group $(n=143)$
\end{tabular} & $\begin{array}{c}\text { Difference }(95 \% \\
\text { CI) or RR }(95 \% \\
\text { CI) }\end{array}$ \\
\hline \multicolumn{7}{|c|}{ Symptoms in peak winter season, November-February, mean (SD) } \\
\hline $\begin{array}{c}\text { Symptom-free days } / 2 \\
\text { wk }\end{array}$ & $11.6(2.6)$ & $10.5(2.9)$ & $\begin{array}{c}0.91(0.31 \text { to } \\
1.51)^{\mathrm{b}}\end{array}$ & $11.6(2.5)$ & $10.9(3.2)$ & $\begin{array}{c}0.96(0.39 \text { to } \\
1.52)^{\mathrm{b}}\end{array}$ \\
\hline Symptom nights/2 wk & $1.8(2.1)$ & $2.7(2.5)$ & $\begin{array}{c}-0.73(-1.22 \text { to }- \\
0.25)^{\mathrm{b}}\end{array}$ & $1.6(2.3)$ & $2.0(2.5)$ & $\begin{array}{c}-0.63(-1.09 \text { to }- \\
0.18)^{\mathrm{b}}\end{array}$ \\
\hline $\begin{array}{l}\text { Days with activity } \\
\text { limitation } / 2 \mathrm{wk}\end{array}$ & $1.2(1.8)$ & $1.9(2.2)$ & $\begin{array}{c}-0.48(-0.92 \text { to }- \\
0.03)^{b}\end{array}$ & $1.4(2.2)$ & $1.7(2.4)$ & $\begin{array}{c}-0.44(-0.87 \text { to }- \\
0.22)^{\mathrm{b}}\end{array}$ \\
\hline $\begin{array}{c}\text { Days with rescue } \\
\text { medication use } / 2 \mathrm{wk}\end{array}$ & $1.7(2.1)$ & $2.9(2.7)$ & $\begin{array}{c}-1.08(-1.58 \text { to }- \\
0.57)^{\mathrm{b}}\end{array}$ & $1.5(2.2)$ & $2.4(2.6)$ & $\begin{array}{c}-1.04(-1.51 \text { to }- \\
0.56)^{b}\end{array}$ \\
\hline $\begin{array}{l}\text { Days absent due to } \\
\text { asthma/2 wk }\end{array}$ & $0.4(0.7)$ & $0.5(0.7)$ & $\begin{array}{c}-0.11(-0.26 \text { to } \\
0.04)^{b}\end{array}$ & $0.3(0.6)$ & $0.5(0.7)$ & $\begin{array}{c}-0.22(-0.36 \text { to }- \\
0.07)^{\mathrm{b}} \\
\end{array}$ \\
\hline $\begin{array}{c}\geq 1 \text { Visit for acute } \\
\text { exacerbation of asthma, } \\
\text { No. (\%) }\end{array}$ & $16(13)$ & $25(21)$ & $\begin{array}{c}0.76(0.42 \text { to } \\
1.36)^{c}\end{array}$ & $15(11)$ & 24(17) & $\begin{array}{l}0.55(0.26 \text { to } \\
1.15)^{\mathrm{c}}\end{array}$ \\
\hline
\end{tabular}

Table 3: Outcomes for the peak winter season stratified by smoke exposure.

Abbreviations: CI, confidence interval; RR, relative risk.

aResults of the multivariate analysis are adjusted for baseline symptoms, child's age, sex, race, caregiver's education, insurance, and maternal depression.

bValues are expressed as difference (95\% CI).

cValues are expressed as RR (95\% CI).

\section{Comments}

The School-Based Asthma Therapy intervention improved outcomes across multiple measures for urban children with asthma. Children receiving the intervention experienced almost 1 symptom-free day per 2 weeks more than children in the control group. This translates into approximately 2.5 weeks of additional symptom-free days during a school year. In addition, children in the treatment group had fewer days with activity limitation, had fewer days of school missed, and were less likely to have an exacerbation that required treatment with systemic corticosteroids. The validity and generalizability of our data are strengthened by the randomized study design, blinded assessments of outcomes, communitybased recruitment through schools, and the use of existing resources (eg, school nurses) to deliver the main component of the intervention. This program has the potential to serve as a model for improved asthma care in urban communities. A few other studies have included implementation of guideline-based asthma care in schools. One study in Alabama found a significant effect of school-based delivery of preventive medications on improvement in asthma control [37]. Additionally, a study in Dallas, Texas, evaluated school-based delivery of preventive medications. The researchers found improvements in measures of asthma severity in a beforeand-after evaluation, but no comparison group was examined. Other school-based studies for children with asthma have involved predominantly educational interventions to empower families to improve asthma management [38-46]. Most have not focused on medical management [47] and have had modest results, suggesting that more intensive management is needed. Collaborations with schools provide the opportunity to reach high-risk children and target those in greatest need of assistance, regardless of their contacts with the health care system. Delivery of preventive asthma treatment is complicated by issues including family stress, poverty, poor access to care, and difficulties in communication that prevent PCPs from providing optimal care. Some proposed solutions to this problem have involved costly interventions that are difficult to sustain. Innovative methods of delivering preventive care through schools 
are being evaluated for many chronic conditions, and because schools already routinely provide daily medications for other conditions such as attentiondeficit/ hyperactivity disorder, the provision of daily asthma preventive medications potentially represents a simple system change to improve adherence. Importantly, in this study we found improved outcomes for children with and without smoke exposure in the home.

This is in contrast to our previous study, where beneficial effects were seen only for children not exposed to smoke in the home. We enhanced our current intervention with 2 significant modifications in hopes of improving its effectiveness among smoke-exposed children. First, in our prior study we may have undertreated some of the children by keeping them on the same dose of medication during the school year. This is particularly pertinent for those exposed to smoke because studies of adult patients with asthma $[48,49]$ indicate reduced effectiveness of inhaled corticosteroids in decreasing inflammation among patients who smoke. Therefore, we implemented symptom-based medication dose adjustments according to guideline recommendations, and $48 \%$ of children in the treatment group received a step-up in therapy during the study. Second, we implemented an ETS reduction program for smoke-exposed children in the treatment group in hopes of decreasing their exposure to smoke. This study was designed to test the impact of a system change on the effectiveness of care. We cannot determine with certainty which component of the intervention was most beneficial in the treatment group but rather can conclude that the system of care can be effective for young urban children with asthma. However, our primary findings were independent of any change in the child's cotinine level, suggesting that the school-based care component alone is effective in reducing symptoms.

It is important to note that the control group likely experienced improved asthma care simply through their participation in the study. We notified each PCP of the child's asthma severity and required the PCP's authorization before randomization. We also called the parents of children in both groups monthly and asked them to recall the child's symptoms. Increased awareness by both parents and PCPs likely caused a conservative bias in the analyses. While interviewers for the outcomes assessments were masked to the child's group allocation, blinding of parents, children, and PCPs was not possible. This could influence self-report outcome measures; however, distinct events such as exacerbations and absenteeism are less likely to be biased. Lastly, the study

Nadia Mahmoud AA. Critical Appraisal on Randomized Controlled Trial to Improve Care for Urban Children with Asthma. Public H Open Acc 2019, 3(2): 000146. findings can be generalized only to similar urban populations.

Compared with usual care, the School-Based Asthma Therapy program significantly improved asthma symptoms and decreased exacerbations among urban children with persistent asthma. This program is particularly important because it can reach large numbers of high-risk children and could potentially reduce disparities between poor and non-poor children. The intervention is widely applicable for asthma care in communities nationwide as well as for management of other chronic diseases. Additional efforts are now needed to evaluate the costs of the intervention and to develop dissemination strategies.

\section{References}

1. Akinbami LJ (2006) Centers for Disease Control and Prevention National Center for Health Statistics. The state of childhood asthma, United States, 1980-2005. Adv Data 381(381): 1-24.

2. Bloom B, Dey AN (2006) Summary health statistics for US children: National Health Interview Survey, 2004. Vital Health Stat 10(227): 1-85.

3. Wennergren G, Kristjansson S, Strannegard IL (1996) Decrease in hospitalization for treatment of childhood asthma with increased use of antiinflammatory treatment, despite an increase in prevalence of asthma. J Allergy Clin Immunol 97(3): 742-748.

4. Donahue JG, Weiss ST, Livingston JM, Goetsch MA, Greineder DK, et al. (1997) Inhaled steroids and the risk of hospitalization for asthma. JAMA 277(11): 887-891.

5. (2002) National Asthma Education and Prevention Program. NAEPP Expert Panel Report: Guidelines for the Diagnosis and Management of Asthma: Update on Selected Topics 2002. National Heart, Lung, and Blood Institute, National Institutes of Health; Bethesda, MD: NIH publication 02-5075.

6. (2007) National Asthma Education and Prevention Program. Expert Panel Report III: Guidelines for the Diagnosis and Management of Asthma. National Heart, Lung, and Blood Institute, National Institutes of Health; Bethesda, MD, NIH publication 07-4051.

7. Halterman JS, Aligne CA, Auinger P, McBride JT, Szilagyi PG (2000) Inadequate therapy for asthma 
among children in the United States. Pediatrics 105(1pt 3): 272-276.

8. Carr W, Zeitel L, Weiss K (1992) Variations in asthma hospitalizations and deaths in New York City. Am J Public Health 82(1): 59-65.

9. Targonski PV, Persky VW, Orris P, Addington W (1994) Trends in asthma mortality among African Americans and whites in Chicago, 1968 through 1991. Am J Public Health 84(11): 1830-1833.

10. Weiss KB, Sullivan SD, Lyttle CS (2000) Trends in the cost of illness for asthma in the United States, 19851994. J Allergy Clin Immunol 106(3): 493-499.

11. Weiss KB, Wagener DK (1990) Changing patterns of asthma mortality: identifying target populations at high risk. JAMA 264(13): 1683-1687.

12. Diaz T, Sturm T, Matte T, Bindra M, Lawler K, et al. (2000) Medication use among children with asthma in East Harlem. Pediatrics 105(6): 1188-1193.

13. Ortega AN, Gergen PJ, Paltiel AD, Bauchner H, Belanger KD, et al. (2002) Impact of site of care, race, and Hispanic ethnicity on medication use for childhood asthma. Pediatrics 109(1).

14. Akinbami LJ, LaFleur BJ, Schoendorf KC (2002) Racial and income disparities in childhood asthma in the United States. Ambul Pediatr 2(5): 382-387.

15. (2004) Centers for Disease Control and Prevention. Cigarette smoking among adults: United States. MMWR Morb Mortal Wkly Rep 54(44): 1121-1124.

16. Fagnano M, Conn KM, Halterman JS (2008) Environmental tobacco smoke and behaviors of inner-city children with asthma. Ambul Pediatr 8(5): 288-293.

17. Mannino DM, Caraballo R, Benowitz N, Repace J (2001) Predictors of cotinine levels in US children: data from the Third National Health and Nutrition Examination Survey. Chest 120(3): 718-724.

18. Weaver VM, Davoli CT, Murphy SE, Sunyer J, Heller PJ, et al. (1996) Environmental tobacco smoke exposure in inner-city children. Cancer Epidemiol Biomarkers Prev 5(2): 135-137.

19. Halterman JS, Borrelli B, Tremblay P, Conn KM, Fagnano M, et al. (2008) Screening for environmental tobacco smoke exposure among inner-city children with asthma. Pediatrics 122(6): 1277-1283.

20. Mannino DM, Homa DM, Redd SC (2002) Involuntary smoking and asthma severity in children: data from the Third National Health and Nutrition Examination Survey. Chest 122(2): 409-415.

21. Chilmonczyk BA, Salmun LM, Megathlin KN, Neveux LM, Palomaki GE, et al. (1993) Association between exposure to environmental tobacco smoke and exacerbations of asthma in children. $\mathrm{N}$ Engl J Med 328(23): 1665-1669.

22. (2000) Committee on the Assessment of Asthma and Indoor Air, Division of Health Promotion and Disease Prevention, Institute of Medicine. Clearing the Air: Asthma and Indoor Air Exposures. National Academies Press, Washington.

23. Morkjaroenpong V, Rand CS, Butz AM, Huss K, Eggleston P, et al. (2002) Environmental tobacco smoke exposure and nocturnal symptoms among inner-city children with asthma. J Allergy Clin Immunol 110(1): 147-153.

24. Evans R, Gergen PJ, Mitchell H, Kattan M, Kercsmar C, et al. (1999) A randomized clinical trial to reduce asthma morbidity among inner-city children: results of the National Cooperative Inner-City Asthma Study. J Pediatr 135(3): 332-338.

25. Morgan WJ, Crain EF, Gruchalla RS (2004) Inner-City Asthma Study Group. Results of a homebased environmental intervention among urban children with asthma. N Engl J Med 351(11): 1068-1080.

26. Halterman JS, Borrelli B, Fisher S, Szilagyi P, Yoos L (2008) Improving care for urban children with asthma: design and methods of the School-Based Asthma Therapy (SBAT) trial. J Asthma 45(4): 279286.

27. Halterman JS, Szilagyi PG, Yoos HL, Conn KM, Kaczorowski JM, et al. (2004) Benefits of a schoolbased asthma treatment program in the absence of secondhand smoke exposure: results of a randomized clinical trial. Arch Pediatr Adolesc Med 158(5): 460467.

28. LaForce CF, Pearlman DS, Ruff ME, Silvers WS, Weinstein SW, et al. (2000) Efficacy and safety of dry powder fluticasone propionate in children with 
persistent asthma. Ann Allergy Asthma Immunol. 85(5): 407-415.

29. Miller WR, Rollnick, S (1991) Motivational Interviewing: Preparing People to Change Addictive Behavior. Guilford Press, New York.

30. Borrelli B, Riekert KA, Weinstein A, Rathier L (2007) Brief motivational interviewing as a clinical strategy to promote asthma medication adherence. J Allergy Clin Immunol 120(5): 1023-1030.

31. Borrelli B, McQuaid EL, Becker B, Hammond K, Papandonatos G, et al. (2002) Motivating parents of kids with asthma to quit smoking: the PAQS project. Health Educ Res 17(5): 659-669.

32. Borrelli B, McQuaid EL, Novak SP, Hammond SK, Becker B (2010) Motivating Latino caregivers of children with asthma to quit smoking: a randomized trial. J Consult Clin Psychol 78(1): 34-43.

33. Szefler SJ (2001) Challenges in assessing outcomes for pediatric asthma. J Allergy Clin Immunol 107(5): S456-S464.

34. Kessler RC, Barker PR, Colpe LJ, Epstein JF, Gfroerer JC, et al. (2003) Screening for serious mental illness in the general population. Arch Gen Psychiatry 60(2): 184-189.

35. Schafer JL (1997) Analysis of Incomplete Multivariate Data. Chapman \& Hall/CRC; Boca Raton, pp: 10.

36. Rubin, DB (1987) Multiple Imputation for Nonresponse in Surveys. John Wiley \& Sons, New York.

37. Gerald LB, McClure LA, Mangan JM, Harrington KF, Gibson L, et al. (2009) Increasing adherence to inhaled steroid therapy among schoolchildren: randomized, controlled trial of school-based supervised asthma therapy. Pediatrics 123(2): 466474.

38. McEwen M, Johnson P, Neatherlin J, Millard MW, Lawrence G (1998) School-based management of chronic asthma among inner-city African-American schoolchildren in Dallas, Texas. J Sch Health 68(5): 196-201.

39. Magzamen S, Patel B, Davis A, Edelstein J, Tager IB (2008) Kickin Asthma: school-based asthma education in an urban community. J Sch Health 78(12): 655-665.

40. Zivkovic Z, Radic S, Cerovic S, Vukasinovic Z (2008) Asthma School Program in children and their parents. World J Pediatr 4(4): 267-273.

41. McWhirter J, McCann D, Coleman H, Calvert M, Warner J (2008) Can schools promote the health of children with asthma? Health Educ Res 23(6): 917930.

42. Tinkelman DG, Schwartz A (2004) School-based asthma disease management. J Asthma 41(4): 455462.

43. Velsor FB, Pigott TD, Louloudes A (2004) The effects of a school-based intervention on the self-care and health of African-American inner-city children with asthma. J Pediatr Nurs 19(4): 247-256.

44. Bruzzese JM, Markman LB, Appel D, Webber M (2001) An evaluation of Open Airways for Schools: using college students as instructors. J Asthma 38(4): 337342.

45. Evans D, Clark NM, Feldman CH, Rips J, Kaplan D, et al. (1987) A school health education program for children with asthma aged 8-11 years. Health Educ Q 14(3): 267-279.

46. Horner SD (1998) Using the Open Airways curriculum to improve self-care for third grade children with asthma. J Sch Health 68(8): 329-333.

47. Christiansen SC, Martin SB, Schleicher NC, Koziol JA, Mathews KP, et al. (1997) Evaluation of a schoolbased asthma education program for inner-city children. J Allergy Clin Immunol 100(5): 613-617.

48. Cox G, Whitehead L, Dolovich M, Jordana M, Gauldie J (1999) A randomized controlled trial on the effect of inhaled corticosteroids on airways inflammation in adult c igarette smokers. Chest 115(5): 1271-1277.

49. Chalmers GW, Macleod KJ, Little SA, Thomson LJ, McSharry CP, et al. (2002) Influence of cigarette smoking on inhaled corticosteroid treatment in mild asthma. Thorax 57(3): 226-230. 